\title{
Effects of different dosages and frequencies of fertigation on growth and yield of cucumber (Cucumis sativus L.) grown in soilless culture
}

\author{
Nguyen H. Pham*, Hung, T. Huynh, \& Vy T. T. Nguyen
}

Faculty of Agronomy, Nong Lam University, Ho Chi Minh City, Vietnam

\begin{abstract}
ARTICLE INFO
Research Paper

Received: February 01, 2019

Revised: May 07, 2019

Accepted: May 11, 2019

\section{Keywords}

Cucumber

Dosages of nutrient solution

Fertigation frequences

Soilless culture

\section{${ }^{*}$ Corresponding author}

Pham Huu Nguyen

Email: phnguyen@hcmuaf.edu.vn
\end{abstract}

\begin{abstract}
Crop yield of cucumber cultivated by soilless culture technique is most likely affected by growing media and fertigation-frequency. Growing media and fertigation-frequency have become important factors affecting crop yields in the technique of soilless culture in general and cucumber in particular. The objective of this study was to determine the appropriate dosages and frequencies of fertigation for growth, development and yield of cucumber grown in the soilless culture under plastic house conditions in Ho Chi Minh City. The expriment was conducted in strip-plot design with three replicates; the vertical factor (A) including three different dosages of nutrient solution was applied variously based on plant growth stages $\left(\mathrm{A}_{1}\right.$ : combination of 226,280 and $236 \mathrm{~mL} /$ plant/ day applied in three different periods from 0 to 3,3 to 5 and after 5 weeks of planting, respectively; $\mathrm{A}_{2}: 339,420$ and 359 $\mathrm{mL} /$ plant/day; and $\mathrm{A}_{3}: 452,560$ and $472 \mathrm{~mL} /$ plant/day). The horizontal factor (B) was four different fertigation frequencies of $2,3,4$ and 5 times/day. The results showed that cucumber fertigated with the nutrient solution having concentration of $452 \mathrm{~mL} /$ plant/day (from 0 to 3 weeks), $560 \mathrm{~mL} /$ plant (from 3 to 5 weeks) and $472 \mathrm{~mL} /$ plant (after 5 weeks) in combination with the fertigation frequency of 5 times/day had the best plant height $(333.5 \mathrm{~cm})$, number of leaves per plant (40.9 leaves/plant), the highest absolute yield $\left(12.65 \mathrm{~kg} / \mathrm{m}^{2}\right)$, and commercial yield $12.52 \mathrm{~kg} / \mathrm{m}^{2}$, and this fertigation regime also resulted in the highest profit $\left(64,275,400 \mathrm{VND} / 1000 \mathrm{~m}^{2}\right)$ and return on investment (1.07).
\end{abstract}

Cited as: Pham, N. H., Huynh, H. T., \& Nguyen, V. T. T. (2019). Effects of different dosages and frequencies of fertigation on growth and yield of cucumber (Cucumis sativus L.) grown in soilless culture. The Journal of Agriculture and Development 18(1), 44-53. 


\title{
Ảnh hưởng của liều lượng và tần suất tưởi dinh dưỡng đến sinh trưởng, phát triển và năng suất của dưa leo (Cucumis sativus L.) canh tác không đất
}

\author{
Phạm Hữu Nguyên*, Huỳnh Thanh Hùng \& Nguyễn Thị Tú Vy \\ Khoa Nông Học, Trường Đại Học Nông Lâm TP. Hồ Chí Minh, TP. Hồ Chí Minh
}

\section{THÔNG TIN BÀI BÁO}

Bài báo khoa học

Ngày nhận: 01/02/2019

Ngày chỉnh sửa: 07/05/2019

Ngày chấp nhận: 11/05/2019

\section{Từ khóa}

Canh tác không đất

Dưa leo

Lượng dung dịch dinh dưỡng

Tần suất tưới dinh dưỡng

\section{*Tác giả liên hệ}

Phạm Hữu Nguyên

Email: phnguyen@hcmuaf.edu.vn

\section{TÓM TẮT}

Trong canh tác không đất, giá thể và tần suất tưới dinh dưỡng là hai yếu tố ảnh hưởng đến năng suất của cây trồng nói chung và dưa leo nói riêng. Mục tiêu của nghiên cứu là nhằm xác định liều lượng và tần suất tưới dinh dưỡng phù hợp để cây dưa leo canh tác không đất sinh trưởng, phát triển tốt cho năng suất và hiệu quả kinh tế cao khi trồng trong nhà màng tại Thành phố Hồ Chí Minh. Thí nghiệm hai yếu tố được bố trí theo kiểu lô sọc (strip-plot design) và 3 lần lặp lại; yếu tố sọc đứng $(\mathrm{A})$ gồm 3 liều lượng dung dịch dinh dưỡng thay đổi theo giai đoạn sinh trưởng của cây $\left(\mathrm{A}_{1}\right.$ : tưới 226 $\mathrm{mL} /$ cây/ngày giai đoạn 3 tuần sau trồng (TST), $280 \mathrm{~mL} /$ cây/ngày giai đoạn 3 - 5 TST, $236 \mathrm{~mL} /$ cây/ngày giai đoạn sau 5 tuần trồng; $\mathrm{A}_{2}$ : tưới $339 \mathrm{~mL} /$ cây/ngày giai đoạn $3 \mathrm{TST}, 420 \mathrm{~mL} /$ cây/ngày giai đoạn $3-5 \mathrm{TST}, 359 \mathrm{~mL} /$ cây/ngày giai đoạn sau 5 tuần trồng; $\mathrm{A}_{3}$ : tưới $452 \mathrm{~mL} /$ cây/ngày giai đoạn $3 \mathrm{TST}, 560 \mathrm{~mL} /$ cây/ngày giai đoạn 3 - 5 TST, $472 \mathrm{~mL} /$ cây/ngày giai đoạn sau 5 tuần trồng); Yếu tố sọc ngang $(\mathrm{B})$ gồm 4 tần suất tưới $\left(\mathrm{B}_{1}: 2\right.$ lần/ngày, $\mathrm{B}_{2}$ : 3 lần/ngày, $\mathrm{B}_{3}: 4$ lần/ngày, $\mathrm{B}_{4}: 5$ lần/ngày). Kết quả cho thây cây dưa leo được tưới với lượng dung dịch $452 \mathrm{~mL} /$ cây/ngày giai đoạn 3 TST, $560 \mathrm{~mL} /$ cây/ngày giai đoạn $3-5 \mathrm{TST}, 472 \mathrm{~mL} /$ cây/ngày giai đoạn sau 5 tuần trồng và tần suất tưới 5 lần/ngày có chiều cao cây cao $(333,5 \mathrm{~cm})$, có số lá nhiều nhất (40,9 lá/cây), có năng suất thực thu và năng suất thương phẩm cao nhất $\left(12,65 \mathrm{~kg} / \mathrm{m}^{2}\right.$ và $\left.12,52 \mathrm{~kg} / \mathrm{m}^{2}\right)$, đồng thời đạt hiệu quả kinh tế cao nhất (lợi nhuận là 64.275 .400 đồng/ $1.000 \mathrm{~m}^{2}$ và tỷ suất lợi nhuận đạt 1,07).

\section{1. Đặt Vấn Đề}

Cây dưa leo chịu hạn rất yếu, thiếu nước cây không những sinh trưởng kém mà còn tích lũy lượng cucurbitaxina gây đắng trong quả (Amera \& ctv., 2009). Dưa leo không chịu được nồng độ phân bón cao và rất nhạy cảm với các trường hợp thiếu dinh dưỡng; trong suốt quá trinh sinh trưởng, dưa leo sử dụng phân kali nhiều nhất, tiếp đến là đạm và lân (Pham \& ctv., 2001). Do vậy, cần cung cấp dinh dưỡng với nồng độ thấp, kết hợp với việc điều chỉnh tần suất và lượng nước tưới phù hợp nhằm đáp ứng nhu cầu dinh dưỡng của cây theo từng giai đoạn sinh trưởng phát triển.

Hệ thống tưới nhỏ giọt kết hợp bón phân qua hệ thống tưới là một trong những sự lựa chọn cho trồng cây trong điều kiện nhà màng, giúp tăng năng suất và hạn chế những sự thất thường của thời tiết và điều kiện tự nhiên đồng thời giúp tiết kiệm nước (Mao \& ctv., 2003; Le, 2009). Bên cạnh đó, kỹ thuật cung cấp dinh dưỡng tối ưu qua hệ thống tưới nhỏ giọt có thể giảm được lượng dinh dưỡng thất thoát, tăng khả năng hấp thụ các chất dinh dưỡng của cây giúp cây sinh trưởng tốt và tăng chất lượng của quả lúc thu hoạch (Feleafel \& ctv., 2014). Ngoài ra, phương pháp bón phân qua hệ thống tưới nhỏ giọt còn rút ngắn thời gian phát triển của cây trồng (Jeff, 2005). Tuy nhiên, các nghiên cứu ban đầu về ảnh hưởng của tần suất và lượng dinh dưỡng tưới qua hệ thống nhỏ giọt đến sinh trưởng và phát triển của cây dưa leo vẫn chưa đưa ra được kết luận cụ thể với các minh chứng khoa học rõ ràng. Xuất phát từ thực tế 
đó, nghiên cứu được thực hiện nhằm tìm ra được lượng dinh dưỡng và tần suất tưới thích hợp qua hệ thống tưới nhỏ giọt cho cây dưa leo canh tác không đất.

\section{Vật Liệu và Phương Pháp Nghiên Cứu}

\subsection{Thời gian và địa điểm thí nghiệm}

Nghiên cứu được tiến hành từ tháng 10/2016 đến tháng 12/2016 trong điều kiện nhà lưới tại Trại Thực nghiệm Khoa Nông học, Trường Đại học Nông Lâm TP.HCM.

\section{2. Điều kiện canh tác}

Điều kiện thời tiết trong nhà lưới thí nghiệm được đo bằng máy đo nhiệt độ, ẩm độ đặt cách mặt đất $1,5 \mathrm{~m}$, tiến hành theo dõi vào lúc 9:00 giờ sáng, 12:00 giờ trưa, 15:00 giờ hàng ngày và lây trung bình. Kết quả ghi nhận cho thây nhiệt độ trong điều kiện thí nghiệm biến động từ 33,3 - $35,7^{0} \mathrm{C}$ cao hơn mức nhiệt độ tối ưu cho canh tác dưa leo là $25-30^{\circ} \mathrm{C}$, ẩm độ trung bình biến động từ 54,6 - 60,3\%.

Giá thể trồng là $50 \%$ xơ dừa đã được ngâm trong dung dịch nước vôi $2,5 \%$ và $50 \%$ cát đã rửa bằng nước sạch phơi khô 3 ngày dể tiệt trùng. Hệ thống tưới nhỏ giọt không hồi lưu được áp dung trong thí nghiệm.

\subsection{Vật liệu nghiên cứu}

Giống dưa leo được sử dụng trong thí nghiệm là giống Galaxy102 với một số đặc tính theo mô tả của nhà sản xuất: thân to, nhiều nhánh, quả suôn, dài từ 17 - $18 \mathrm{~cm}$, quả màu xanh, ruột nhỏ, ăn giòn, ngọt, thu hoạch sau 34 - 35 ngày sau gieo, thời gian thu hoạch kéo dài đến 35 ngày. Kháng bệnh tốt, có khả năng đậu quả tốt trong điều kiện nhiệt độ cao, năng suất trung bình từ $4,0-4,5 \mathrm{~kg} /$ cây và khoảng $6-7$ tấn $/ 1.000 \mathrm{~m}^{2}$.

\subsection{Phương pháp nghiên cứu}

Thí nghiệm được bố trí theo kiểu lô sọc (strip plot design), hai yếu tố gồm 12 nghiệm thức và 3 lần lặp lại. Yếu tố sọc đứng $(\mathrm{A})$ : Ba liều lượng dung dịch dinh dưỡng thay đổi theo từng giai đoạn sinh trưởng của cây dưa leo (Bảng 1) tương ứng với nồng độ N-P-K áp dụng khác nhau ở các giai đoạn (Bảng 2 ) được cải tiến từ công thức của FAO theo kết quả nghiên cứu của Tran (2015);
Ngoài các yếu tố thí nghiệm là $\mathrm{N}, \mathrm{P}$ và $\mathrm{K}$ thay đổi theo các giai đoạn sinh trưởng phát triển của cây dưa leo, các nguyên tố trung vi lượng sử dụng từ đầu đến cuối vụ với nồng độ: Ca: 182,0ppm; Mg: 99,6 ppm; Fe: 1,6 ppm; Cu: 0,03 ppm; Mn: 0,6 ppm; Zn: 2,0 ppm; B: 0,4 ppm; Mo: 0,7 ppm. $\mathrm{EC}$ được điều chỉnh ở mức $1,7-2,5 \mathrm{mS} / \mathrm{cm}$ và $\mathrm{pH}$ được giữ ổn định ở mức 5,5 - 6,0 để đảm bảo dung dịch dinh dưỡng luôn ổn định. Yếu tố sọc ngang (B) là 4 tần suất tưới dinh dưỡng tương ứng từ 2 đến 5 lần/ngày (bắt đầu tưới từ lúc 8 giờ và cách 2 giờ tưới 1 lần theo số lần tưới của các nghiệm thức, thời gian tưới được trình bày ở Bảng 3 ). Diện tích mỗi ô thí nghiệm là $1,5 \mathrm{~m}^{2}$, tổng diện tích khu thí nghiệm $80,4 \mathrm{~m}^{2}$. Mỗi ô thí nghiệm gồm 10 bầu giá thể có kích thước $25 \mathrm{~cm} \times 25 \mathrm{~cm}$, trồng 1 cây/bầu giá thể, khoảng cách trồng 30 $\mathrm{cm} \times 50 \mathrm{~cm}$ tương ứng với mật độ trồng là 6.667 cây $/ 1.000 \mathrm{~m}^{2}$. Mỗi ô thí nghiệm chọn 5 cây theo đường zigzac để theo dõi. Theo dõi các chỉ tiêu sinh trưởng của cây như chiều cao cây $(\mathrm{cm} /$ cây), số lá (lá/cây), số nhánh cấp 1 (nhánh/cây) vào thời điểm 47 NST. Các chỉ tiêu về năng suất như số quả trung bình 1 cây, khối lượng quả trên cây, khối lượng trung bình 1 quả, năng suất thực tế, năng suất thương phẩm. Các chỉ tiêu về đặc điểm và chất lượng quả được lấy từ đợt thu hoạch thứ 2 bao gồm chiều dài quả, đường kính quả, độ cứng (Đo bằng máy Zwitt/Roell Texture analyzer, đo bằng đầu đo $5 \mathrm{~mm}$, đo 3 lần/trái $\times 3$ trái/nghiệm thức), hàm lượng nitrat (Phân tích theo phương pháp so màu TCVN 8742/2011), hàm lượng chất khô (Sấy dưa leo ở $72^{0} \mathrm{C}$ đến khi khối lượng không đổi và tính hàm lượng chất khô).

Số liệu được thu thập và xử lý thô bằng Microsoft Excel. Phân tích phương sai ANOVA và trắc nghiệm phân hạng Duncan bằng phần mềm SAS 9.1 bản postable.

\section{Kết Quả và Thảo Luận}

3.1. Ảnh hưởng của lượng dung dịch và tần suất tưới đến các chỉ tiêu sinh trưởng của cây dưa leo trồng vụ Thu Đông 2016 tại Thủ Đức, Thành phố Hồ Chí Minh

Bảng 4 cho thấy sự khác biệt về chiều cao cây khi được tưới với lượng dung dịch khác nhau rất có ý nghĩa về mặt thống kê, trong đó cây được tưới với lượng dung dịch 452 - 560 - 472 mL/cây/ngày đạt cao nhất $331,7 \mathrm{~cm}$ khác biệt không có ý nghĩa so với cây được tưới với lượng dung dịch 339 - 420 - 354 mL/cây/ngày nhưng 
Bảng 1. Lượng dinh dưỡng (mL/cây/ngày) cung cấp cho cây theo các giai đoạn sinh trưởng

\begin{tabular}{ccccc}
\hline Lượng dinh dưỡng & \multicolumn{3}{c}{ Giai đoạn sinh trưởng } & \multirow{2}{*}{ Kí hiệu } \\
\cline { 2 - 5 }$(\mathrm{mL} /$ cây $/$ ngày $)$ & $<3$ tuần sau trồng & $3-5$ tuần sau trồng & Sau 5 tuần & \\
\hline $\mathrm{A}_{1}$ & 226 & 280 & 236 & $226-280-236$ \\
$\mathrm{~A}_{2}$ & 339 & 420 & 354 & $339-420-354$ \\
$\mathrm{~A}_{3}$ & 452 & 560 & 472 & $452-560-472$ \\
\hline
\end{tabular}

Bảng 2. Nồng độ các nguyên tố dinh dưỡng theo các giai đoạn sinh trưởng

\begin{tabular}{cccc}
\hline \multirow{2}{*}{ Nồng độ $(\mathrm{ppm})$} & \multicolumn{3}{c}{ Giai đoạn sinh trưởng } \\
\cline { 2 - 4 } & $<3$ tuần sau trồng & $3-5$ tuần sau trồng & Sau 5 tuần \\
\hline $\mathrm{N}$ & 174,6 & 166,3 & 174,6 \\
$\mathrm{P}$ & 13,3 & 14,0 & 13,3 \\
$\mathrm{~K}$ & 230,0 & 230,0 & 241,5 \\
\hline
\end{tabular}

Bảng 3. Thời gian tưới (phút/cây/ngày) dung dịch cho cây dưa leo theo từng giai đoạn sinh trưởng

\begin{tabular}{cccccc}
\hline \multirow{2}{*}{ Giai đoạn sinh trưởng } & Lượng dung dịch $(\mathrm{A})$ & \multicolumn{4}{c}{ Tần suất tưới (B) (lần/ngày) } \\
\cline { 3 - 6 } & $(\mathrm{mL} /$ cây/ngày) & 2 & 3 & 4 & 5 \\
\hline \multirow{3}{*}{$<3$ tuần sau trồng } & $226-280-236$ & 11,3 & 7,5 & 5,6 & 4,5 \\
& $339-420-354$ & 17,0 & 11,3 & 8,5 & 6,8 \\
& $452-560-472$ & 22,6 & 15,1 & 11,3 & 9,0 \\
\hline \multirow{3}{*}{3 - 5 tuần sau trồng } & $226-280-236$ & 14,0 & 9,3 & 7,0 & 5,6 \\
& $339-420-354$ & 21,0 & 14,0 & 10,5 & 8,4 \\
& $452-560-472$ & 28,0 & 18,7 & 14,0 & 11,2 \\
\hline \multirow{2}{*}{ Sau 5 tuần } & $226-280-236$ & 11,8 & 7,0 & 4,9 & 4,7 \\
& $339-420-354$ & 17,7 & 11,8 & 8,9 & 7,1 \\
& $452-560-472$ & 23,6 & 15,7 & 11,8 & 9,4 \\
\hline
\end{tabular}

Bảng 4. Ảnh hưởng của lượng dung dịch và tần suất tưới đến các chỉ tiêu sinh trưởng của cây dưa leo trồng vụ Thu Đông 2016 tại Thủ Đức, Thành phố Hồ Chí Minh tại thời điểm 47 NST

\begin{tabular}{|c|c|c|c|c|c|c|}
\hline \multirow{2}{*}{ Chỉ tiêu } & \multirow{2}{*}{$\begin{array}{c}\text { Lượng dung dịch (A) } \\
\text { (mL/cây/ngày) }\end{array}$} & \multicolumn{4}{|c|}{ Tần suất tưới (B) (lần/ngày) } & \multirow{2}{*}{$\mathrm{TB}_{\mathrm{A}}$} \\
\hline & & 2 & 3 & 4 & 5 & \\
\hline \multirow{5}{*}{$\begin{array}{l}\text { Chiều cao cây } \\
\qquad(\mathrm{cm})\end{array}$} & $226-280-236$ & 253,5 & 276,0 & 277,1 & 270,1 & $269,2^{\mathrm{b}}$ \\
\hline & $339-420-354$ & 278,7 & 293,3 & 297,4 & 311,7 & $295,3^{\mathrm{ab}}$ \\
\hline & $452-560-472$ & 336,3 & 323,3 & 333,7 & 333,5 & $331,7^{\mathrm{a}}$ \\
\hline & $\mathrm{TB}_{\mathrm{B}}$ & 289,5 & 297,6 & 302,8 & 305,1 & \\
\hline & $\mathrm{CV}(\%)=4,59 ; \mathrm{F}_{\mathrm{A}}=$ & $3,20^{* *}$ & $=0,42^{\mathrm{n}}$ & $\mathrm{A} * \mathrm{~B}=$ & & \\
\hline \multirow{5}{*}{$\begin{array}{l}\text { Số lá } \\
\text { (lá/cây) }\end{array}$} & $226-280-236$ & 30,7 & 33,1 & 33,4 & 31,7 & $32,3^{\mathrm{c}}$ \\
\hline & $339-420-354$ & 34,8 & 35,7 & 37,1 & 38,9 & $36,6^{\mathrm{b}}$ \\
\hline & $452-560-472$ & 40,3 & 39,9 & 40,7 & 40,9 & $40,5^{\mathrm{a}}$ \\
\hline & $\mathrm{TB}_{\mathrm{B}}$ & 35,3 & 36,2 & 37,0 & 37,2 & \\
\hline & $\mathrm{CV}(\%)=3,57 ; \mathrm{F}_{\mathrm{A}}=$ &, $12^{* *}$ & $=1,23^{\mathrm{n}}$ & $\mathrm{A} * \mathrm{~B}=$ & & \\
\hline \multirow{5}{*}{$\begin{array}{l}\text { Số nhánh cấp } 1 \\
\text { (nhánh/cây) }\end{array}$} & $226-280-236$ & 4,1 & 4,2 & 4,2 & 5,1 & $4,4^{b}$ \\
\hline & $339-420-354$ & 5,7 & 5,7 & 6,0 & 6,5 & $6,0^{\mathrm{ab}}$ \\
\hline & $452-560-472$ & 8,2 & 8,6 & 9,2 & 9,1 & $8,8^{\mathrm{a}}$ \\
\hline & $\mathrm{TB}_{\mathrm{B}}$ & $6,0^{\mathrm{b}}$ & $6,2^{\mathrm{b}}$ & $6,5^{\mathrm{b}}$ & $6,9^{\mathrm{a}}$ & \\
\hline & $\mathrm{CV}(\%)=6,64 ; \mathrm{F}_{\mathrm{A}}=$ & $9,38^{* *}$ & $=6,19^{*}$ & $*_{\mathrm{B}}=0$ & & \\
\hline
\end{tabular}


khác biệt rất có ý nghĩa so với chiều cao cây được tưới với lượng dung dịch 226 - 280 - 236 mL/cây/ngày chỉ đạt 269,2 cm/cây. Sự khác biệt về chiều cao cây dưa leo khi được tưới với các tần suất khác nhau khác biệt không có ý nghĩa về mặt thống kê, tuy nhiên chiều cao cây dưa leo được tưới với tần suất càng cao thì có xu hướng cao hơn những tần suất tưới thấp. Sự tương tác giữa các lượng dung dịch và tần suất tưới đến chiều cao cây khác biệt không có ý nghĩa về mặt thống kê.

Tương tự chiều cao cây, sự khác biệt về số lá trên thân chính được tưới với các lượng dung dịch khác nhau rất có ý nghĩa về mặt thống kê (Bảng 4); trong đó số lá cao nhất ở cây được tưới với lượng dung dịch 452 - 560 - 472 mL/cây/ngày dạt 40,5 lá/cây, khác biệt rất có ý nghĩa so với số lá của cây được tưới 2 lượng dung dịch còn lại. Số lá trên thân chính tăng dần theo tần suất tưới nhưng sự khác biệt về số lá trên thân chính khi được tưới với các tần suất khác nhau khác biệt không có ý nghĩa thống kê. Sự tương tác giữa các lượng dung dịch và tần suất tưới đến số lá khác biệt không có ý nghĩa về mặt thống kê.

3.2. Ảnh hưởng của lượng dung dịch và tần suất tưởi đến các yếu tố cấu thành năng suất và năng suất của cây dưa leo trồng vụ Thu Đông 2016 tại Thủ Đức, Thành phố Hồ Chí Minh

Trong điều kiện đồng nhất nhưng cây dưa leo được tưới với lượng dung dịch khác nhau sẽ có tỷ lệ đậu quả khác nhau, điều này do lượng dung dịch dinh dưỡng của mỗi liều lượng quyết định, đồng thời số quả trên cây là yếu tố trực tiếp quyết định đến năng suất và tỷ lệ thuận với năng suất. Năng suất được cấu thành bởi số quả trung bình 1 cây, khối lượng trung bình 1 quả và số cây (Bảng 5). Kết quả Bảng 5 cho thấy dưa leo được tưới với lượng dung dịch 452 - 560 - $472 \mathrm{~mL} /$ cây/ngày phát triển vượt trội về các chỉ tiêu sinh trưởng sinh thực, số lượng hoa cái, số lượng quả và tỉ lệ đậu quả cao hơn và khác biệt rất có ý nghĩa so với cây dưa leo được tưới ở lượng dung dich còn lại. Việc gia tăng số lần tưới trong ngày cũng ảnh hưởng đến quá trình ra hoa và đậu quả của cây, tần suất tưới 5 lần/ngày giúp gia tăng số lượng hoa cái và tî̉ lệ đậu quả ở cây so với cây được trồng ở các nghiệm thức khác. Sự tương tác giữa lượng dung dịch dinh dưỡng và tần suất tưới đến số hoa cái, số quả và tỷ lệ đậu quả khác biệt không có ý nghĩa thống kê.
Kết quả Bảng 5 cho thấy khối lượng trung bình (TB) 1 quả của các cây được tưới với lượng dung dịch khác nhau biến động từ 127,9 - 154,9 g/quả, sự khác biệt này rất có ý nghĩa về mặt thống kê. Khối lượng TB một quả cao nhất đạt 154,9 g/quả ở cây được tưới với lượng dung dịch 452 - 560 472 mL/cây/ngày, khác biệt có ý nghĩa so với quả của cây được tưới với 2 lượng dung dịch còn lại. Khối lượng TB 1 quả giữa các cây được tưới với tần suất khác nhau khác biệt không có ý nghĩa về mặt thống kê. Sự tương tác giữa lượng dung dịch và tần suất tưới đến khối lượng $\mathrm{TB} 1$ quả khác biệt không có ý nghĩa về mặt thống kê.

Sự khác biệt về khối lượng TB quả trên cây giữa các cây được tưới với các lượng dung dịch khác nhau rất có ý nghĩa về mặt thống kê (Bảng 5), khối lượng TB quả trên cây dao động từ 1,21 - 2,11 kg/cây; trong đó khối lượng TB quả trên cây cao nhất đạt $2,11 \mathrm{~kg} /$ cây ở cây được tưới với lượng dung dịch 452 - 560 - $472 \mathrm{~mL} /$ cây/ngày, khác biệt có ý nghĩa so với cây được tưới với 2 lượng dung dịch còn lại. Khối lượng TB quả trên cây giữa cây được tưới với tần suất khác nhau khác biệt rất có ý nghĩa về mặt thống kê, trong đó khối lượng quả TB trên cây cao nhất ở cây được tưới với tần suất 5 lần/ngày $(1,69 \mathrm{~kg} /$ cây) và 4 lần/ngày $(1,68 \mathrm{~kg} /$ cây), khác biệt rất có ý nghĩa so với cây được tưới với tần suất 2 lần/ngày và 3 lần/ngày. Sự tương tác giữa lượng dung dịch và tần suất tưới đến khối lượng quả TB 1 cây khác biệt không có ý nghĩa về mặt thống kê. Kết quả trình bày về năng suất lý thuyết (NSLT, $\mathrm{kg} / \mathrm{m}^{2}$ ) ở Bảng 6 cho thấy rằng NSLT giữa cây được tưới với các liều lượng dinh dưỡng khác nhau khác biệt rất có ý nghĩa thống kê. Cây dưa leo được tưới với lượng dinh dưỡng 452 - 560 - $472 \mathrm{~mL} /$ cây/ngày có NSLT cao nhất $(14,06 \mathrm{~kg} /$ cây) và khác biệt rất có ý nghĩa so với cây được tưới với 2 liều lượng dung dịch còn lại. Tương tự với liều lượng dinh dưỡng, sự khác biệt về NSLT giữa cây được tưới với tần suất khác nhau khác biệt rất có ý nghĩa về mặt thống kê. Năng suất lý thuyết tăng dần theo tần suất tưới từ 2 dến 5 lần/ngày và cao nhất khi tưới với tần suất 5 lần/ngày đạt $11,26 \mathrm{~kg} /$ cây và khác biệt không có ý nghĩa so với tưới 4 lần/ngày $(11,21 \mathrm{~kg} /$ cây) và 3 lần/ngày (10,89 kg/cây), thấp nhất khi tưới với tần suất 2 lần/ngày chỉ đạt $10,67 \mathrm{~kg} /$ cây. Sự tương tác giữa các lượng dung dịch và tần suất tưới đến NSLT khác biệt không có ý nghĩa về mặt thống kê.

Sự khác biệt về năng suất thực thu (NSTT, $\mathrm{kg} / \mathrm{m}^{2}$ ) giữa các cây được tưới với lượng dung 
Bảng 5. Ảnh hưởng của lượng dung dịch và tần suất tưới đến tỷ lệ đậu quả và các yếu tố cấu cấu thành năng suất của cây dưa leo trồng vụ Thu Đông 2016 tại Thủ Đức, Thành phố Hồ Chí Minh

\begin{tabular}{|c|c|c|c|c|c|c|}
\hline \multirow{2}{*}{ Chỉ tiêu } & \multirow{2}{*}{$\begin{array}{l}\text { Lượng dung dịch }(\mathrm{A}) \\
\text { (mL/cây/ngày) }\end{array}$} & \multicolumn{4}{|c|}{ Tần suất tưới (B) (lần/ngày) } & \multirow{2}{*}{$\mathrm{TB}_{\mathrm{A}}$} \\
\hline & & 2 & 3 & 4 & 5 & \\
\hline \multirow{5}{*}{$\begin{array}{c}\text { Hoa cái } \\
\text { trung bình cây } \\
\text { (hoa/cây) }\end{array}$} & $226-280-236$ & $\overline{14,1}$ & 14,4 & 15,3 & 15,4 & $14,8^{\mathrm{c}}$ \\
\hline & $339-420-354$ & 16,1 & 16,6 & 16,3 & 16,6 & $15,4^{\mathrm{b}}$ \\
\hline & $452-560-472$ & 17,4 & 17,3 & 17,7 & 18,7 & $17,8^{\mathrm{a}}$ \\
\hline & $\mathrm{TB}_{\mathrm{B}}$ & $15,9^{\mathrm{b}}$ & $16,1^{\mathrm{b}}$ & $16,4^{\mathrm{ab}}$ & $16,9^{\mathrm{a}}$ & \\
\hline & \multicolumn{6}{|c|}{$\mathrm{CV}(\%)=2,82 ; \mathrm{F}_{\mathrm{A}}=52,22^{* *} ; \mathrm{F}_{\mathrm{B}}=7,44^{*} ; \mathrm{F}_{\mathrm{A} * \mathrm{~B}}=2,10^{\mathrm{ns}}$} \\
\hline \multirow{5}{*}{$\begin{array}{l}\text { Số quả } \\
\text { trung bình cây } \\
\text { (quả/cây) }\end{array}$} & $226-280-236$ & 10,0 & 10,2 & 11,0 & 11,1 & $10,6^{\mathrm{c}}$ \\
\hline & $339-420-354$ & 12,1 & 12,5 & 12,3 & 12,6 & $12,4^{\mathrm{b}}$ \\
\hline & $452-560-472$ & 14,1 & 14,1 & 14,5 & 15,2 & $14,5^{\mathrm{a}}$ \\
\hline & $\mathrm{TB}_{\mathrm{B}}$ & $12,1^{\mathrm{c}}$ & $12,2^{\mathrm{bc}}$ & $12,6^{\mathrm{ab}}$ & $13,0^{\mathrm{a}}$ & \\
\hline & \multicolumn{6}{|c|}{$\mathrm{CV}(\%)=2,55 ; \mathrm{F}_{\mathrm{A}}=107,58^{* *} ; \mathrm{F}_{\mathrm{B}}=9,01^{*} ; \mathrm{F}_{\mathrm{A}^{*} \mathrm{~B}}=2,27^{\mathrm{ns}}$} \\
\hline \multirow{5}{*}{$\begin{array}{c}\text { Tỷ lệ đậu quả } \\
(\%)\end{array}$} & $226-280-236$ & 71,1 & 70,7 & 71,9 & 71,7 & $71,3^{\mathrm{b}}$ \\
\hline & $339-420-354$ & 74,8 & 75,3 & 75,7 & 75,9 & $75,4^{\mathrm{b}}$ \\
\hline & $452-560-472$ & 81,3 & 81,3 & 81,9 & 81,1 & $81,4^{\mathrm{a}}$ \\
\hline & $\mathrm{TB}_{\mathrm{B}}$ & 75,7 & 75,8 & 76,5 & 76,2 & \\
\hline & \multicolumn{6}{|c|}{$\mathrm{CV}(\%)=1,20 ; \mathrm{F}_{\mathrm{A}}=57,11^{* *} ; \mathrm{F}_{\mathrm{B}}=0,66^{\mathrm{ns}} ; \mathrm{F}_{\mathrm{A} * \mathrm{~B}}=0,43^{\mathrm{ns}}$} \\
\hline \multirow{5}{*}{$\begin{array}{l}\text { Khối lượng } \\
\text { trung bình } 1 \text { quả } \\
\text { (g/quả) }\end{array}$} & $226-280-236$ & 127,6 & 127,0 & 128,1 & 128,9 & $127,9^{\mathrm{b}}$ \\
\hline & $339-420-354$ & 140,0 & 138,6 & 136,7 & 137,6 & $138,2^{\mathrm{b}}$ \\
\hline & $452-560-472$ & 152,0 & 155,0 & 155,7 & 156,8 & $154,9^{\mathrm{a}}$ \\
\hline & $\mathrm{TB}_{\mathrm{B}}$ & 139,8 & 140,2 & 140,2 & 141,1 & \\
\hline & \multicolumn{6}{|c|}{$\mathrm{CV}(\%)=2,47 ; \mathrm{F}_{\mathrm{A}}=36,44^{* *} ; \mathrm{F}_{\mathrm{B}}=0,11^{\mathrm{ns}} ; \mathrm{F}_{\mathrm{A} * \mathrm{~B}}=0,76^{\mathrm{ns}}$} \\
\hline \multirow{5}{*}{$\begin{array}{l}\text { Khối lượng } \\
\text { trung bình quả } \\
\text { trên } 1 \text { cây } \\
\text { (kg/cây) }\end{array}$} & $226-280-236$ & 1,15 & 1,18 & 1,25 & 1,27 & $1,21^{\mathrm{c}}$ \\
\hline & $339-420-354$ & 1,56 & 1,62 & 1,66 & 1,67 & $1,63^{\mathrm{b}}$ \\
\hline & $452-560-472$ & 2,08 & 2,09 & 2,13 & 2,13 & $2,11^{\mathrm{a}}$ \\
\hline & $\mathrm{TB}_{\mathrm{B}}$ & $1,60^{\mathrm{b}}$ & $1,63^{\mathrm{ab}}$ & $1,68^{\mathrm{a}}$ & $1,69^{\mathrm{a}}$ & \\
\hline & \multicolumn{6}{|c|}{$\mathrm{CV}(\%)=1,43 ; \mathrm{F}_{\mathrm{A}}=90,93^{* *} ; \mathrm{F}_{\mathrm{B}}=14,17^{* *} ; \mathrm{F}_{\mathrm{A} * \mathrm{~B}}=1,80^{\mathrm{ns}}$} \\
\hline
\end{tabular}

a-c Trong cùng một cột hoặc hàng, các chữ số có cùng ký tự theo sau khác biệt không có ý nghĩa thống kê. ns: khác biệt không có ý nghĩa về mặt thống kê $(P>0,05)$; $^{*}$ : khác biệt có ý nghĩa về mặt thống kê $(0,01<P \leq 0,05)$; **: khác biệt rất có ý nghĩa về mặt thống kê $(P \leq 0,01)$.

dịch khác nhau khác biệt rất có ý nghĩa về mặt thống kê, NSTT dao động từ 7,36 - 12,15 kg/m² (Bảng 6); trong đó cao nhất là cây được tưới với lượng dung dịch 452 - 560 - $472 \mathrm{~mL} /$ cây/ngày đạt $12,15 \mathrm{~kg} /$ cây, khác biệt rất có ý nghĩa so với cây được tưới với 2 lượng dung dịch còn lại. Sự khác biệt về NSTT giữa các cây được tưới với tần suất khác nhau khác biệt không có ý nghĩa về mặt thống kê. Sự tương tác giữa lượng dung dịch và tần suất tưới đến NSTT khác biệt không có ý nghĩa về mặt thống kê.

Sự khác biệt năng suất thương phẩm (NSTP, $\mathrm{kg} / \mathrm{m}^{2}$ ) của cây dưa leo được tưới với các lượng dung dịch khác nhau khác biệt rất có ý nghĩa về mặt thống kê, NSTP dao động từ 7,16 - 11,20 $\mathrm{kg} / \mathrm{m}^{2}$. Trong đó, cây dưa leo đạt NSTP cao nhất khi được tưới với lượng dung dịch 452 - 560 $472 \mathrm{~mL} /$ cây/ngày $\left(11,20 \mathrm{~kg} / \mathrm{m}^{2}\right)$, khác biệt rất có ý nghĩa so với cây được tưới với 2 lượng dung dịch còn lại. Trong khi đó, cùng giống dưa leo Galaxy102 được trồng trong điều kiện nhà lưới tại thành phố Hồ Chí Minh nhưng với mật độ là 8.333 cây $/ 1.000 \mathrm{~m}^{2}$ và trồng trong giá thể $100 \%$ XD thì chỉ đạt NSTP là $9,83 \mathrm{~kg} / \mathrm{m}^{2}$ (Nguyen, 2016). Năng suất thương phẩm giữa các cây được tưới với các tần suất khác nhau khác biệt không có ý nghĩa thống kê. Sự tương tác giữa lượng dung dịch và tần suất tưới đến NSTP cũng khác biệt không có ý nghĩa thống kê.

\section{3. Ảnh hưởng của lượng dung dịch và tần suất tưới đến kích thước, chất lượng quả dưa leo trồng vụ Thu Đông 2016 tại Thủ Đức, thành phố Hồ Chí Minh}

Kết quả Bảng 7 và Hình $1,2,3$ cho thấy: Chiều dài quả ở cây được tưới với lượng dung dịch và tần suất càng cao thì quả có xu hướng 
Bảng 6. Ảnh hưởng của lượng dung dịch và tần suất tưới đến năng suất của cây dưa leo trồng vụ Thu Đông 2016 tại Thủ Đức, Thành phố Hồ Chí Minh

\begin{tabular}{|c|c|c|c|c|c|c|}
\hline \multirow{2}{*}{$\begin{array}{l}\text { Năng suất } \\
\left(\mathrm{kg} / \mathrm{m}^{2}\right)\end{array}$} & \multirow{2}{*}{$\begin{array}{l}\text { Lượng dung dịch }(\mathrm{A}) \\
\text { (mL/cây/ngày) }\end{array}$} & \multicolumn{4}{|c|}{ Tần suất tưới (B) (lần/ngày) } & \multirow{2}{*}{$\mathrm{TB}_{\mathrm{A}}$} \\
\hline & & 2 & 3 & 4 & 5 & \\
\hline \multirow{5}{*}{ Lý thuyết } & $226-280-236$ & 7,69 & $\overline{7,89}$ & 8,36 & 8,45 & $8,10^{\mathrm{c}}$ \\
\hline & $339-420-354$ & 10,41 & 10,83 & 11,07 & 11,11 & $10,86^{\mathrm{b}}$ \\
\hline & $452-560-472$ & 13,90 & 13,94 & 14,18 & 14,23 & $14,06^{\mathrm{a}}$ \\
\hline & $\mathrm{TB}_{\mathrm{B}}$ & $10,67^{\mathrm{b}}$ & $10,89^{\mathrm{ab}}$ & $11,21^{\mathrm{a}}$ & $11,26^{\mathrm{a}}$ & \\
\hline & \multicolumn{6}{|c|}{$\mathrm{CV}(\%)=1,45 ; \mathrm{F}_{\mathrm{A}}=91,08^{* *} ; \mathrm{F}_{\mathrm{B}}=13,72^{* *} ; \mathrm{F}_{\mathrm{A} * \mathrm{~B}}=1,73^{\mathrm{ns}}$} \\
\hline \multirow{5}{*}{ Thực tế } & $226-280-236$ & 6,96 & 7,17 & 7,61 & 7,70 & $7,36^{\mathrm{c}}$ \\
\hline & $339-420-354$ & 9,28 & 9,48 & 9,50 & 9,95 & $9,55^{\mathrm{b}}$ \\
\hline & $452-560-472$ & 11,86 & 11,96 & 12,13 & 12,65 & $12,15^{\mathrm{a}}$ \\
\hline & $\mathrm{TB}_{\mathrm{B}}$ & 9,37 & 9,54 & 9,75 & 10,10 & \\
\hline & \multicolumn{6}{|c|}{$\mathrm{CV}(\%)=4,25 ; \mathrm{F}_{\mathrm{A}}=144,60^{* *} ; \mathrm{F}_{\mathrm{B}}=3,45^{\mathrm{ns}} ; \mathrm{F}_{\mathrm{A} * \mathrm{~B}}=0,26^{\mathrm{ns}}$} \\
\hline \multirow{5}{*}{ Thương phẩm } & $226-280-236$ & 6,76 & 6,96 & 7,42 & 7,49 & $7,16^{\mathrm{c}}$ \\
\hline & $339-420-354$ & 9,06 & 9,27 & 9,29 & 9,74 & $9,34^{\mathrm{b}}$ \\
\hline & $452-560-472$ & 11,73 & 11,77 & 11,97 & 12,52 & $11,20^{\mathrm{a}}$ \\
\hline & $\mathrm{TB}_{\mathrm{B}}$ & 9,18 & 9,33 & 9,56 & 9,92 & \\
\hline & \multicolumn{6}{|c|}{$\mathrm{CV}(\%)=4,41 ; \mathrm{F}_{\mathrm{A}}=141,85^{* *} ; \mathrm{F}_{\mathrm{B}}=3,47^{\mathrm{ns}} ; \mathrm{F}_{\mathrm{A}^{*} \mathrm{~B}}=0,29^{\mathrm{ns}}$} \\
\hline
\end{tabular}

a-c Trong cùng một cột hoặc hàng, các chữ số có cùng ký tư theo sau khác biệt không có ý nghĩa thống kê. ns: khác biệt không có ý nghĩa về mặt thống kê $(P>0,05)$;*: khác biệt có ý nghĩa về mặt thống kê $(0,01<P \leq 0,05)$;**: khác biệt rất có ý nghĩa về mặt thống kê $(P \leq 0,01)$.

càng dài tuy nhiên sự khác biệt này không có ý nghĩa thống kê. Cây dưa leo được tưới với lượng dung dịch $452-560-472 \mathrm{~mL} /$ cây/ngày và tần suất tưới 5 lần/ngày có chiều dài quả dài nhất $15,4 \mathrm{~cm}$. Đường kính quả dưa leo ở cây được tưới với lượng dung dịch và tần suất tưới càng cao thì quả có xu hướng càng lớn. Cây dưa leo được tưới với lượng dung dịch 452 - 560 - $472 \mathrm{~mL} /$ cây/ngày và tần suất tưới 5 lần/ngày có đường kính quả lớn đạt $3,8 \mathrm{~cm}$.

Bảng 8 cho thấy: Trong điều kiện thí nghiệm, khi tưới với 3 lượng dung dịch dinh dưỡng khác nhau thì độ cứng quả dưa leo biến động từ 22,7 - 23,9 N. Khi tưới với liều lượng dinh dưỡng 452 - 560 - $472 \mathrm{~mL} /$ cây/ngày thì quả dưa leo có độ cứng cao nhất. Khi tăng tần suất tưới từ 2 lên 4 lần/ngày, độ cứng quả dưa leo tăng từ $23,6 \mathrm{~N}$ đến $24,1 \mathrm{~N}$ nhưng khi tăng lên 5 lần/ngày thì độ cứng quả giảm xuống chỉ còn $22,1 \mathrm{~N}$.

Hàm lượng nitrat là một trong những chỉ tiêu để đánh giá mức độ an toàn của rau. Có nhiều yếu tố ảnh hưởng đến hàm lượng trong rau, trong đó dinh dưỡng giữ vai trò quan trọng nhất. Qua kết quả phân tích ở Bảng 8 cho thấy: việc sử dụng các lượng dung dịch trong thí nghiệm ở các nghiệm thức dẫn đến hàm lượng nitrat trong quả biến động từ $12,06-12,21 \mathrm{mg} / \mathrm{kg}$ và đều dưới ngưỡng cho phép của bộ Y tế $(\leq 150 \mathrm{mg} / \mathrm{kg}$ quả tươi) nên đảm bảo sức khỏe cho người tiêu dùng.
Trong điều kiện thí nghiệm, khi tăng lượng dung dịch tưới cho cây thì hàm lượng nitrat trong quả cũng tăng dần. Trong khi đó hàm lượng nitrat trong quả biến động từ 12,14 đến $12,16 \mathrm{mg} / \mathrm{kg}$ khi tăng tần suất tưới từ 2 lên 5 lần.

Hàm lượng chất khô: Khi tăng lượng dung dịch tưới cho cây thì hàm lượng chất khô trong quả giảm dần. Khi tưới với tần suất 2 và 3 lần/ngày, quả dưa leo có hàm lượng chất khô tương đương nhau $(1,44 \%)$. Khi tưới với tần suất 4 và 5 lần/ngày, quả dưa leo có hàm lượng chất khô tương đương nhau (1,42\%). Tưới với lượng dinh dưỡng 226 - $280-236 \mathrm{~mL} /$ cây/ngày với tần suất tưới 2 hoặc 3 lần/ngày, quả dưa leo có hàm lượng chất khồ cao nhất $(1,62 \%)$.

Qua kết quả Bảng 9 cho thấy: Cây dưa leo được tưới với lượng dung dịch 452 - 560 - 472 $\mathrm{mL} /$ cây/ngày và tần suất tưới 5 lần/ngày đạt lợi nhuận cao nhất (64.275.400 đồng/1.000 m²), kế tiếp là cây dưa leo được tưới với lượng dung dịch $452-560-472 \mathrm{~mL} /$ cây/ngày và tần suất tưới 4 lần/ngày $\left(58.615 .400\right.$ đồng $\left./ 1.000 \mathrm{~m}^{2}\right)$. Cây dưa leo được tưới với lượng dung dịch 226 - 280 - 236 $\mathrm{mL} /$ cây/ngày với tần suất tưới 2 lần/ngày cho lợi nhuận thấp nhất chỉ đạt 10.776.980 đồng/1.000 $\mathrm{m}^{2} /$ vụ. Bên cạnh đó, do được tưới với lượng dung dịch thấp nhất nên cây dưa leo sinh trưởng phát triển không tốt và cho năng suất thấp nhất $(6,76$ $\left.\mathrm{kg} / \mathrm{m}^{2}\right)$, quả có vị đắng nên không phù hợp với 
Bảng 7. Ảnh hưởng của lượng dung dịch và tần suất tưới đến kích thước quả dưa leo (cm)

\begin{tabular}{|c|c|c|c|c|c|c|}
\hline \multirow{2}{*}{ Chỉ tiêu } & \multirow{2}{*}{$\begin{array}{c}\text { Lượng dung dịch (A) } \\
\text { (mL/cây/ngày) }\end{array}$} & \multicolumn{4}{|c|}{ Tần suất tưới (B) (lần/ngày) } & \multirow{2}{*}{$\mathrm{TB}_{\mathrm{A}}$} \\
\hline & & 2 & 3 & 4 & 5 & \\
\hline \multirow{5}{*}{$\begin{array}{l}\text { Chiều dài quả } \\
(\mathrm{cm})\end{array}$} & $226-280-236$ & 14,5 & 14,6 & 14,9 & 14,5 & 14,6 \\
\hline & $339-420-354$ & 14,7 & 14,6 & 14,3 & 14,7 & 14,6 \\
\hline & $452-560-472$ & 14,7 & 14,7 & 14,9 & 15,4 & 14,9 \\
\hline & $\mathrm{TB}_{\mathrm{B}}$ & 14,6 & 14,6 & 14,7 & 14,9 & \\
\hline & $\mathrm{CV}(\%)=3,80 ; \mathrm{F}_{\mathrm{A}}=$ & $36^{\text {ns }} ; \mathrm{H}$ & $0,18^{\mathrm{n}}$ & $B=0$ & & \\
\hline \multirow{5}{*}{$\begin{array}{l}\text { Đường kính quả } \\
\qquad(\mathrm{cm})\end{array}$} & $226-280-236$ & 3,2 & 3,3 & 3,5 & 3,5 & 3,4 \\
\hline & $339-420-354$ & 3,6 & 3,6 & 3,6 & 3,6 & 3,6 \\
\hline & $452-560-472$ & 3,6 & 3,6 & 3,9 & 3,8 & 3,7 \\
\hline & $\mathrm{TB}_{\mathrm{B}}$ & 3,5 & 3,5 & 3,7 & 3,6 & \\
\hline & \multicolumn{6}{|c|}{$\mathrm{CV}(\%)=8,87 ; \mathrm{F}_{\mathrm{A}}=3,03^{\mathrm{ns}} ; \mathrm{F}_{\mathrm{B}}=1,92^{\mathrm{ns}} ; \mathrm{F}_{\mathrm{A}} *_{\mathrm{B}}=0,24^{\mathrm{ns}}$} \\
\hline
\end{tabular}

Bảng 8. Ảnh hưởng của lượng dung dịch và tần suất tưới đến chất lượng quả dưa leo

\begin{tabular}{|c|c|c|c|c|c|c|}
\hline \multirow{2}{*}{ Chỉ tiêu } & \multirow{2}{*}{$\begin{array}{l}\text { Lượng dung dịch (A) } \\
\text { (mL/cây/ngày) }\end{array}$} & \multicolumn{4}{|c|}{ Tần suất tưới (B) (lần/ngày) } & \multirow{2}{*}{$\mathrm{TB}_{\mathrm{A}}$} \\
\hline & & 2 & 3 & 4 & 5 & \\
\hline \multirow{4}{*}{ Độ cứng (N) } & $226-280-236$ & 22,4 & 22,6 & 25,1 & 20,8 & 22,7 \\
\hline & $339-420-354$ & 25,1 & 23,6 & 22,7 & 22,9 & 23,6 \\
\hline & $452-560-472$ & 23,3 & 25,1 & 24,6 & 22,5 & 23,9 \\
\hline & $\mathrm{TB}_{\mathrm{B}}$ & 23,6 & 23,8 & 24,1 & 22,1 & \\
\hline \multirow{4}{*}{$\begin{array}{l}\text { Hàm lượng nitrat } \\
\text { (mg/kg) }\end{array}$} & $226-280-236$ & 12,05 & 12,06 & 12,07 & 12,07 & 12,06 \\
\hline & $339-420-354$ & 12,17 & 12,16 & 12,18 & 12,18 & 12,17 \\
\hline & $452-560-472$ & 12,21 & 12,21 & 12,19 & 12,22 & 12,21 \\
\hline & $\mathrm{TB}_{\mathrm{B}}$ & 12,14 & 12,14 & 12,15 & 12,16 & \\
\hline \multirow{4}{*}{$\begin{array}{c}\text { Hàm lượng } \\
\text { chất khôo } \\
(\%)\end{array}$} & $226-280-236$ & 1,62 & 1,62 & 1,61 & 1,61 & 1,62 \\
\hline & $339-420-354$ & 1,45 & 1,44 & 1,40 & 1,40 & 1,42 \\
\hline & $452-560-472$ & 1,26 & 1,26 & 1,25 & 1,24 & 1,25 \\
\hline & $\mathrm{TB}_{\mathrm{B}}$ & 1,44 & 1,44 & 1,42 & 1,42 & \\
\hline
\end{tabular}

Bảng 9. Ảnh hưởng của lượng dung dịch và tần suất tưới đến hiệu quả kinh tế cây dưa leo trồng vụ Thu Đông 2016 tại Thủ Đức, Thành phố Hồ Chí Minh

\begin{tabular}{|c|c|c|c|c|c|}
\hline \multirow{2}{*}{ Chỉ tiêu } & \multirow{2}{*}{$\begin{array}{l}\text { Lượng dung dịch }(\mathrm{A}) \\
\text { (mL/cây/ngày) }\end{array}$} & \multicolumn{4}{|c|}{ Tần suất tưới (B) (lần/ngày) } \\
\hline & & 2 & 3 & 4 & 5 \\
\hline \multirow{3}{*}{$\begin{array}{c}\text { Tổng chi } \\
\text { (đồng/1.000 m²/vụ) }\end{array}$} & $\mathrm{A}_{1}$ & 55.383 .020 & 55.383 .020 & 55.383 .020 & 55.383 .020 \\
\hline & $\mathrm{A}_{2}$ & 57.111 .400 & 57.111 .400 & 57.111 .400 & 57.111 .400 \\
\hline & $\mathrm{A}_{3}$ & 60.044 .600 & 60.044 .600 & 60.044 .600 & 60.044 .600 \\
\hline \multirow{3}{*}{$\begin{array}{c}\text { Tổng thu } \\
\text { (đồng/1.000 m²/vụ) }\end{array}$} & $\mathrm{A}_{1}$ & 66.160 .000 & 68.160 .000 & 72.760 .000 & 73.380 .000 \\
\hline & $\mathrm{A}_{2}$ & 89.000 .000 & 91.340 .000 & 91.380 .000 & 95.880 .000 \\
\hline & $\mathrm{A}_{3}$ & 116.260 .000 & 116.340 .000 & 118.660 .000 & 124.320 .000 \\
\hline \multirow{3}{*}{$\begin{array}{c}\text { Lợi nhuận } \\
\text { (đồng/1.000 m²/vụ) }\end{array}$} & $\mathrm{A}_{1}$ & 10.776 .980 & 12.776 .980 & 17.376 .980 & 17.996 .980 \\
\hline & $\mathrm{A}_{2}$ & 31.888 .600 & 34.228 .600 & 34.268 .600 & 38.768 .600 \\
\hline & $\mathrm{A}_{3}$ & 56.215 .400 & 56.295 .400 & 58.615 .400 & 64.275 .400 \\
\hline \multirow{3}{*}{$\begin{array}{l}\text { Tỷ suất } \\
\text { lợi nhuận }\end{array}$} & $\overline{\mathrm{A}_{1}}$ & 0,19 & 0,23 & 0,31 & 0,32 \\
\hline & $\mathrm{A}_{2}$ & 0,56 & 0,60 & 0,60 & 0,68 \\
\hline & $\mathrm{A}_{3}$ & 0,94 & 0,94 & 0,98 & 1,07 \\
\hline
\end{tabular}

Giá bán: 10.000 đồng/kg (loại 1), 2.000 đồng/kg (loại 2). 

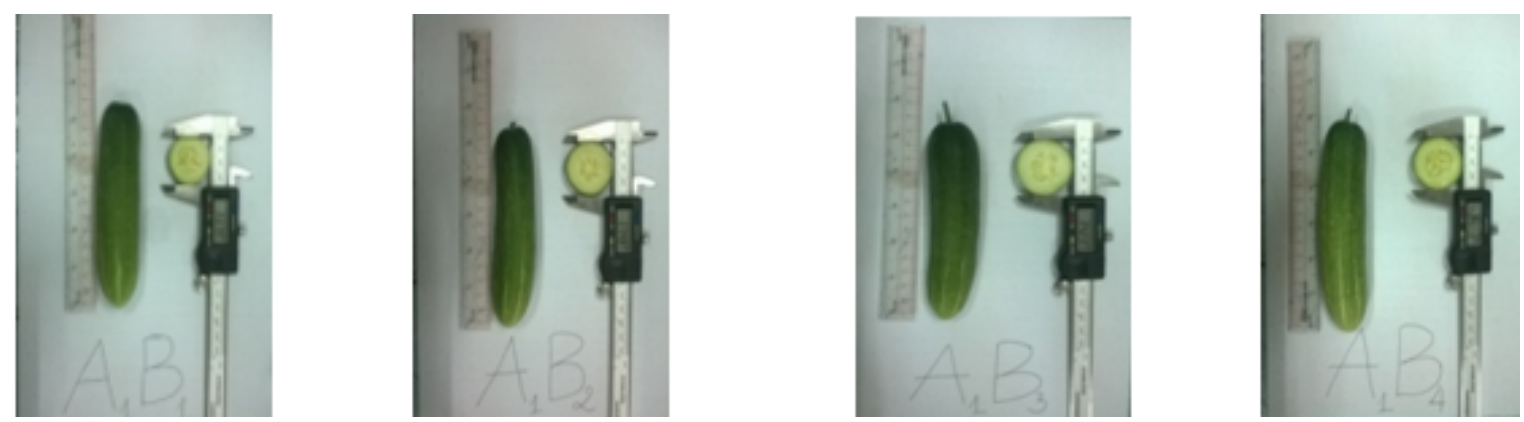

Hình 1. Quả dưa leo ở các cây được tưới lượng 226 - 280 - $336 \mathrm{~mL} /$ cây/ngày theo tần suất tưới.
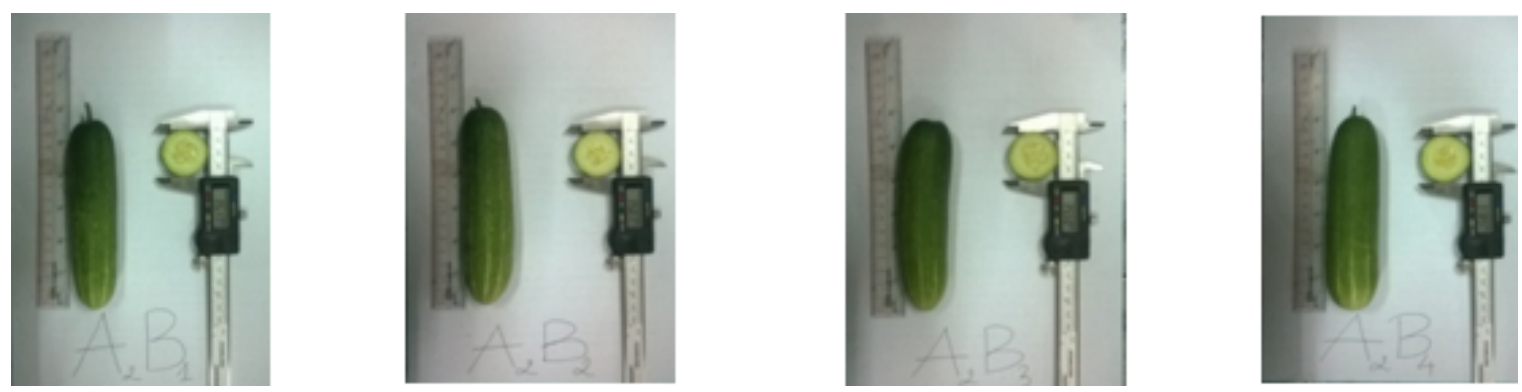

Hình 2. Quả dưa leo ở các cây được tưới lượng 339 - 420 - $354 \mathrm{~mL} /$ cây/ngày theo tần suất tưới.
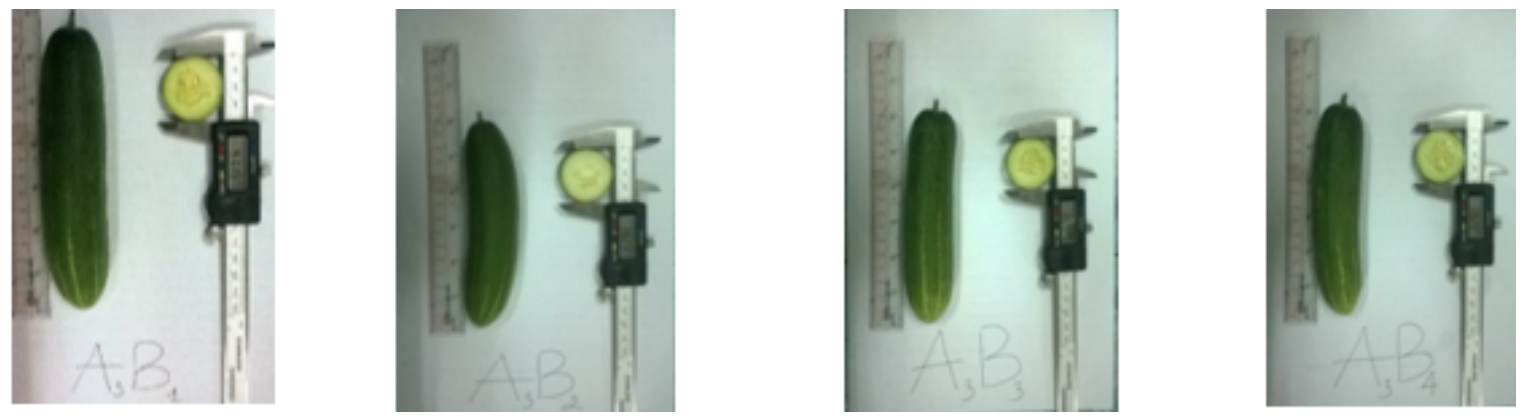

Hình 3. Quả dưa leo ở các cây được tưới 452 - 560 - $472 \mathrm{~mL} /$ cây/ngày theo tần suất tưới.

nhu cầu thị hiếu của người tiêu dùng.

\section{Kết Luận}

Cây dưa leo được tưới với lượng dung dịch 452 $\mathrm{mL} /$ cây/ngày giai đoạn 3 tuần sau trồng, 560 $\mathrm{mL} /$ cây/ngày giai đoạn $3-5$ tuần sau trồng, $472 \mathrm{~mL} /$ cây/ngày giai đoạn sau 5 tuần trồng và tần suất tưới 5 lần/ngày có chiều cao cây cao (333,5cm/cây), có số lá cao nhất (40,9 lá/cây), có năng suất thực thu và năng suất thương phẩm cao nhất $\left(12,65 \mathrm{~kg} / \mathrm{m}^{2}\right.$ và $\left.12,52 \mathrm{~kg} / \mathrm{m}^{2}\right)$ và đạt hiệu quả kinh tế cao nhất (lợi nhuận 64.275.400 đồng/1.000 $\mathrm{m}^{2}$ và tỷ suất lợi nhuận đạt 1,07$)$.

\section{Tài Liệu Tham Khảo (References)}

Amera, K. H., Sally, M. A., \& Jerry, H. L. (2009). Effect of deficit irrigation and fertilization on cucumber. Agronomy Journal 101(6), 1556-1564.

Feleafel, M. N., Mirdad, Z. M., \& Hassan, A. S. (2014). Effects of NPK fertigation rate and starter fertilizer on the growth and yield of cucumber grown in greenhouse. Journal of Agricultural Science 6(9), $81-92$. 
Jeff, W. (2005). Hydroponic Indoor Horticulture. London, England: Pukka Press Ltd.

Le, T. A. (2009). Irrigation and Drainage Systems. Can tho, Vietnam: Can Tho University Publishing House.

Mao, X., Liu, M., Wang, X., Liu, C., Hou, Z., \& Shi, J. (2003). Effects of deficit irrigation on yield and water use of greenhouse grown cucumber in the North China Plain. Agricultural Water Management 61(3), 219-228.

Nguyen, N. T. (2016). Effects of variety and planting space on growth and yield of cucumber (Cucumis sativus L.) grown in soilless culture in Ho Chi Minh City (Unpublished bachelor's thesis). Nong Lam University, Ho Chi Minh City, Vietnam.
Pham, C. H., Tran, H. V., \& Tran, B. T. (2001). Vegetable farming techniques. Ho Chi Minh, Vietnam: Agricultural Publishing House.

Tran, T. T. B. (2015). Effects of four nutritional formulas on growth and yield of cucumber (Cucumis sativus L.) grown in soilless culture in Ho Chi Minh city (Unpublished bachelor's thesis). Nong Lam University, Ho Chi Minh City, Vietnam. 